\title{
THE ADMISSIBILITY OF SCIENTIFIC EVIDENCE IN CRIMINAL CASES
}

\author{
FRED E. INBAU*
}

Sherlock Holmes with his lens and his theories probably has afforded considerably more entertainment to readers of his unique experiences than he has created serious thinking on their part as to the practicability of actually applying such methods and techniques in detecting crime, and in utilizing in criminal trials the evidence resulting therefrom. Other detectives of the fiction world, with the possible exception of Doctor Thorndyke, have done still less to arouse more genuine interest in scientific methods of crime detection. We have been content, it seems, to keep such figures within the veil of our imagination and to reconcile ourselves to ordinary police methods when attempting to solve a crime involving unconventional tactics or motives, to say nothing of the more usual type, in which the scientific approach is equally desirable. Only quite recently has there been any indication of a change in attitude, and this has resulted from the unrelenting pioneering efforts of relatively few individuals qualified to render scientific assistance to law enforcement agencies. The general notion has become a little more widespread, but considered in terms of what might be accomplished the era of scientific evidence has only begun.

During this somewhat transitory period the judiciary, along with the police of this country, is receiving considerable criticism from some quarters for not utilizing to any greater extent the assistance which scientists are prepared to offer in this field. In partial defense for this position a police officer is often prepared to say: "What good are your scientific methods if the facts we obtain by using them are inadmissible as evidence?" He is, as a general rule, entirely unfamiliar with the legal status of testimony or facts of a scientific nature, and his conclusion of inadmissibility is very often erroneous-and even in instances where he is correct he frequently fails to appreciate the advantage of the scientific approach for investigative purposes alone. The layman is still more apt to find the courts responsible for not offering more encouragement to the scientist and to the police in this respect. Lawyers themselves often display guilty complexes when such discussions arise, but they too seem oblivious to the fact that in many of the recorded opinions of the appellate courts of this

*B.S., I930, LL.B., 1932, Tulane University; LL.M., I933, Northwestern University. Instructor in Police Science, Scientific Crime Detection Laboratory, Northwestern University School of Law. Editor, American Journal of Police Science. 
country may be found some of the most interesting detective stories ever written, principally because of the reality of the situation.

Consider, for instance, the case of Magnuson v. State, decided in 1925 by the Supreme Court of Wisconsin. The facts, as stated by that court, may appear to have been taken from a pulp paper magazine rather than from a judicial opinion. But there was no fiction involved. The almost unbelievable mass of scientific evidence presented to the jury was sufficiently convincing to sustain a conviction of murder in the first degree.

A bomb had been sent through the mails, and upon reaching the addressee, who opened the package, there followed an explosion which caused the death of one person and serious injury to another. The only clues with which the police had to work were the remains of the home-made bomb and fragments of the paper-wrapper containing the address.

An examiner of questioned documents who had been consulted suggested that the spelling of the town address (Marsfilld for Marshfield) was characteristic of a person familiar with the Swedish language. The only person known to have any enmity toward the recipient of the package happened to be the only Swede in the vicinity-the defendant, John Magnuson.

From the pieces picked up about the home of the deceased, the bomb was reconstructed, and was found to have been made of a hollow piece of white elm, a piece of gas pipe, a brass tube, and a small piece of steel used' as a trigger. The suspect's premises were inspected. Pieces of gas pipe, of brass tubing, and other materials were seized, including a bottle of ink, and sawdust and shavings from the work bench. A triangular trip or trigger was taken off the suspect's gasoline engine, because of its resemblance to the trigger found in the bomb.

With these materials in hand, counsel for the state set to work to establish the fact that the bomb was manufactured and sent by the defendant. Samples of the defendant's handwriting were introduced in evidence, together with testimony of three of the country's foremost document examiners to the effect that the handwriting found upon the paper wrapper was that of the defendant. Further testimony was admitted which established the fact that a fountain pen with a round point had been used, similar to that found in the defendant's home, and that the ink used to address the package gave the same chemical reaction as that found in the fountain pen. Also, an analysis of the glue used to fasten down the string disclosed the fact that it was the same kind as that found in the defendant's possession. A botanist from the U.S. Forest Service Laboratory testified that the sawdust taken from the defendant's workbench was of white elm-a significant fact because the defendant denied that he had ever worked with elm in his shop. Expert testimony further disclosed the fact that the trigger on the bomb came from the same piece of steel as the trigger taken from the defendant's gas engine. This conclusion was based upon

\footnotetext{
${ }^{2} 187$ Wis. 122, 203 N. W. 749 (1925).
} 
the similarity in the crystalline structure and formation of the two pieces of metal, as revealed in photomicrographs.

All this evidence was admitted by the trial court, and received the approval of the Supreme Court of Wisconsin:

"We have set out the evidence with greater particularity than would ordinarily be warranted under such circumstances, because it discloses what may be done by a diligent prosecuting officer who has an intelligent comprehension of the things that are necessary to establish guilt in a case of this importance. The guilt of the defendant is as conclusively established as it is possible for it to be. It is scarcely conceivable that any jury could find otherwise than did the jury in this case." 2

Is there anything discouraging in the language of this court?

Another very interesting case is State $v$. Clark, decided in $193^{\circ}$ by the Supreme Court of Washington. A young girl was brutally assaulted as she passed through a wooded field on her way home from school. Her assailant had constructed a blind near the path-way, and for this purpose he used twigs and tree branches, which he had cut with a knife. The police apprehended a suspect, but the girl was unable to identify him with any degree of certainty. Nevertheless, science came into play, and secured a conviction where conventional methods of proof would have failed.

At the trial of the culprit, an expert testified and was able to prove, with the aid of photomicrographs, that the knife found in the possession of the accused person was the knife that cut the twigs and tree branches of the blind in which the girl had been assaulted.

The conviction was affirmed, and in its opinion the court had this to say for science in its application to matters pertaining to criminal justice:

"Courts are no longer skeptical that, by the aid of scientific appliances, the identity of a person may be established by fingerprints. There is no difference in principle in the utilization of the photomicrograph to determine that the same tool that made one impression is the same instrument that made another impression. The edge of one blade differs as greatly from the edge of another blade as the lines of one human hand differ from the lines of another. This is a progressive age. The scientific means afforded should be used to apprehend the criminal." 4

The last two remarks should offer encouragement to the men who are devoting their lives to studies of this nature. The entire opinion represents an invitation to them to utilize their most acute methods not only for the purpose of apprehension but also for the purpose of conviction in a court of justice.

In 1929 the New Jersey Court of Errors and Appeals rendered a decision in a case involving a most interesting set of facts-State $v$. Boceadora. ${ }^{5}$ The defendant was suspected of having shot and killed the occupant of a home while in the act of committing burglary. In an effort to determine the defendant's whereabouts at the time of the murder his common law wife was questioned as to her knowledge of

'Id. at I3I, $203 \mathrm{~N}$. W. at 753.

Id. at 549, 287 Pac. at 20.
I56 Wash. 543, 287 Pac. 18 (1930).

I05 N. J. L. 352, I44 Atl. 612 (1929). 
the affair. She finally informed the investigators that on the particular night in question the defendant told her that he had fled from the scene of a burglary and had disposed of his pistol by throwing it away as he ran from the scene of the crime. The weapon was never located.

About a month prior to the murder, another home in the community had been burglarized, and among the articles stolen were some jewelry and a hammerless revolver. For some reason the owner became involved in the present investigation and he identified as his stolen property some jewelry in possession of the defendant's wife. The evidence indicated that this had been given her by the defendant. It was inferred, therefore, that if the defendant had stolen the jewelry he also was guilty of the theft of the revolver. Consequently, if there were any means of connecting that particular weapon with the murder in question, this would constitute a material factor in establishing his guilt.

It so happened-and herein is the strange feature of the case-that the owner of the stolen weapon had fired a bullet from it into the ground near his home, as part of a holiday celebration some year or two previous to the theft. It was suggested that this be retrieved for the purpose of comparison with the fatal missile, since there was no evidence weapon from which a test bullet could be obtained. Fortunately it was found. An examination was made by an expert with the aid of a comparison microscope, and he was permitted to testify at the defendant's trial that this old bullet and the fatal bullet were fired from the same pistol. This evidence the appellate court considered sufficiently reliable to sustain a conviction of first degree murder.

Is there anything discouraging about this case? Certainly it cannot be said that the court considered itself bound by precedent established in dusty old law books, because there was no such precedent for so unusual a case, although the science of firearms identification itself had already received judicial sanction.

Many other equally interesting cases might be mentioned, such as People v. Wallage ${ }^{b}$ and State $v$. Johnson, ${ }^{7}$ to say nothing of the famous Hauptmann case, and others of which we have no judicial record because appeals were not taken to superior courts.

In the Wallage case, principally because of the following facts, an automobile was identified as being the one involved in a hit-and-run accident: similarity in chemical composition between a sample of paint taken from the dented portion of an automobile fender and a specimen of paint present on the shirt worn by the deceased at the time of the accident; the presence, as revealed by a microscopic examination, of minute lines or scratches on the automobile fender where the paint had been rubbed off, which corresponded in number-thirty-one to the inch-with the raised threads in the cloth of the shirt; and the further fact, as stated in the opinion of the expert witness, that from a microscopic examination of other scratches and an examination

' 353 Ill. 95 , 186 N. E. 540 (1933).

${ }^{7} 37$ N. M. 280, 21 Pac. (2d) 813 (x933). 
of the right suspender buckle in the back of the overalls worn by the deceased child, he found that the scratches on the fender were of the "same contour, design and size" as the buckle of the overalls worn by the deceased.

In the Johnson case, finger nail scrapings taken from a young girl, the victim of a criminal assault, and of a suspect, furnished a very convincing bit of evidence indicating the suspect's guilt. An expert found in the debris taken from underneath the deceased's nails several plant fibers colored blue, which he described as identical in appearance with cotton fibers scraped by him from the blue and white overalls worn by the defendant on the night in question. Chemical tests disclosed that the debris removed from underneath the fingernails of both the deceased and the defendant contained, in addition to skin particles, "a number of small bright carmine red particles, highly transparent, ... and identical in color, appearance, and refraction," from which facts it was inferred that the "Kiss-Proof" lipstick worn by the deceased constituted the common origin of both specimens of evidence.

The road to judicial recognition of scientific evidence is not always an easy one, as indicated by the historical development of firearms identification testimony in the state of Illinois. In examples like this the layman finds some support for his criticism of the courts concerning such matters.

In 1923 , in People v. Berkman, ${ }^{8}$ the Supreme Court of Illinois failed to appreciate the significance or the possibilities of this new phase of circumstantial evidence. It even went so far as to label as "preposterous" the suggestion that distinctive markings were impressed upon bullets fired from different pistols of the same caliber and make. In 1930 the same court had before it another case involving the admissibility of firearms identification testimony-People $v$. Fiorita, ${ }^{9}$ in which the decision represents what might be termed the second stage in the progressive evolution toward judicial acceptance in Illinois. The appellate court recognized the accuracy of the science itself but reversed the case because of the incompetency of the expert witness. Instead of branding firearms identification as "preposterous," however, the court stated that while the science was well recognized "both in this country and abroad, testimony based upon it should be admitted with the greatest care. No witness should be permitted to testify regarding the identification of firearms and bullets by the use of this science unless the witness has clearly shown that he is qualified to give such testimony." Notice the change of attitude during that brief seven year period since the decision of the previous case! And then consider the third stage-the decision in the landmark case of People v. Fisher, ${ }^{10}$ decided four months later. In this case firearms identification finally received the stamp of approval by the Illinois Supreme Court. The trial court had heard the testimony of a competent witness so the appellate court, pursuant to the policy laid down in the Fiorita case, completely recognized as trustworthy the same science it had labeled as "preposterous" only five years previously.

${ }^{8} 307$ Ill. 492 , 139 N. E. 9 I (I923).

${ }^{\circ} 339$ Ill. 78,170 N. E. 690 (1930).

${ }^{10} 340$ Ill. 216,172 N. E. 743 (1930). 
This display of caution by the Illinois courts the layman does not seem to understand. In 1923, when the first Illinois case came up for consideration, the science of firearms identification was yet in its infancy. For that reason we should not be surprised to find a court unwilling to accept it as evidence, although the use of the word "preposterous" formed an unnecessary part of the court's opinion. Nevertheless, today there is no longer any question regarding the admissibility of firearms identification evidence, not only in the State of Illinois, but in all other jurisdictions as well. The appellate courts of thirteen states, and one federal circuit court of appeals, have definitely signified their approval of its use in criminal cases, and even though the problem has not presented itself for the consideration of the appellate courts in other jurisdictions, there appears to be no reason to expect a contrary ruling. ${ }^{11}$

Another type of scientific evidence which was utilized by the police long before it received judicial sanction is that of finger-prints. Although for years the science of fingerprint identification played an important part in police investigations, it was not until xgrI that an appellate court in the United States passed upon its admissibility as a link in the chain of circumstances indicating the guilt of an accused individual. In that year, the Supreme Court of Illinois, in People v. Jennings, ${ }^{12}$ took judicial notice of the fact that the finger-prints of any individual are so distinctive as to permit their use for the purpose of identification, and admitted expert testimony as to the similarity between the evidence print and that of the defendant-under the general common law rule that whatever tends to prove a material fact is relevant and competent.

Since the Jennings decision a number of others have been rendered by various state appellate courts upon the subject, among them being the highest tribunals of New Jersey, New York, Arizona, Oklahoma, and North Carolina. In every instance such evidence has been held admissible. Moreover, palm-print evidence occupies the same judicial status, according to the decisions in several cases rendered by the appellate courts of Arizona, Vermont, and Michigan. The courts have even gone to the extent of admitting finger-print evidence in instances where an accused's prints (those used for comparison) have been taken under compulsion. ${ }^{13}$

The one type of scientific evidence with which the courts have done some obviously unnecessary wrangling is that of handwriting identification, one of the principal problems arising in the broader field of expert examination of questioned documents. For historical reasons the courts were very insistent, until recent years, that the only documents which could be used for comparison were those "in the

${ }^{11}$ See Inbau, Scientific Evidence in Criminal Cases: I. Firearms Identification- "Ballistics" (1933) 24 J. CRIMr. L. \& CRIMIN. 825, 842. This article also contains a discussion of some of the related problems in frearms identification such as the determination, from a study of powder burns and shot dispersion, of the distance at which a gun had been fired.

252 Ill. 534,96 N. E. 1077 (I911).

${ }^{23}$ See Inbau, Scientific Evidence in Criminal Cases: III. Finger-prints and Palm-prints (1934) $25 \mathrm{~J}$. CrIM. L. \& CrIMIN. 500-517. 
case for other purposes." This restriction seriously hampered the expert witness, and, as Mr. Albert S. Osborn has remarked, "the whole history of the subject has been clouded by this unfortunate procedure."14 But today, either by statute or by decision, the expert may avail himself of standards for comparison even though they are to be introduced in evidence for that purpose alone. ${ }^{15}$

As to the intrinsic merits of expert examination of handwriting and other documentary evidence, the courts were not so slow in their appreciation. Therefore, with the removal of the restriction upon the use of unrelated standards and a recognition of the advisability and necessity for the use of expert testimony in this field, today an attorney handling a case involving disputed documents may, without much difficulty, present an expert witness in court to prove (with certain limitations in particular instances) any or all of the follow:ng: identity of an anonymous writing; genuineness or spuriousness of a signature; that a certain person did or did not execute a questioned signature or a forgery; the presence of erasures, alterations, substitutions and additions; sequence of writing; the identity of typewritten material; and the identification of materials of writing, such as ink, paper (more generally as to type only), etc. ${ }^{16}$

Another type of evidence of a scientific nature which seems destined to eventually play an impottant rôle in our judicial system, but which is barred at the present time, is that regarding the detection of deception. Several attempts have been made to introduce evidence obtained by the use of so-called "lie-detectors," but in each instance admissibility has been denied. However, even in these adverse decisions the courts have sounded a note of encouragement.

Especially noteworthy in this connection is the language of the District of Columbia Court of Appeals in its decision of Frye v. United States, ${ }^{17}$ which involved the admissibility of a psychologist's testimony regarding a deception test made upon the defendant by the use of a "systolic blood pressure" method. Since very little was known at that time, 1923, about scientific methods of detecting deception, the court may have been inclined to label as "preposterous" the notion that there exists a correlation between blood pressure changes and deception. However, it chose to use the following language:

"Just when a scientific principle of discovery crosses the line between the experimental and demonstrable stages is difficult to define. Somewhere in this, twilight zone the evidential force of the principle must be recognized, and while courts will go a long way in admitting expert testimony deduced from a well-recognized scientific principle or discovery, the thing from which the deduction is made must be sufficiently established to have gained general acceptance in the particular field in which it belongs.

"We think that the systolic blood pressure deception test has not yet gained such standing and scientific recognition among physiological and psychological authorities as would

\footnotetext{
${ }^{14}$ See Osborn, Questioned Documents (2d ed. 1929) 26.

${ }^{15}$ Hall v. State, r7r Ark. 787,286 S. W. 1026 (1926).

${ }^{10} \mathrm{See}$ numcrous cases cited in concluding chapters of OsBorn, op. cit. supra' note 14.

${ }^{17} 54$ App. D. C. 46, 293 Fed. 10r3 (1923), Note (1925) 34 A. L. R. 145.
} 
justify the courts in admitting evidence deduced from the discovery, development, and experiments thus far made."18

Since r923 considerable progress has been made in this field of detecting deception, but still not enough to justify its court application, according to a I933 decision of the Supreme Court of Wisconsin, in State $v$. Bohner. ${ }^{10}$ In this case defense counsel offered to prove by means of a "lie-detector" the truthfulness of the defendant's alibi, which offer the trial court refused. Upon appeal the Supreme Court conceded that the instrument (one recording pulse wave, blood pressure changes and respiratory changes) "may have some utility at present, and may ultimately be of great value in the administration of justice." Nevertheless, the court was of the opinion that a "too hasty acceptance of it during this stage of its development may bring complications and abuses which will overbalance whatever utility it may be assumed to have."20

The possible "complications and abuses" constitute a constant source of concern on the part of those persons actively engaged in this field. They realize, from the data and information already at hand, ${ }^{21}$ that the results of a detection of deception test with a suitable instrument recording pulse wave, blood pressure and respiratory changes, and perhaps other physiological reactions, when conducted and interpreted by a competent and honest individual are worthy of consideration as evidence for or against the defendant in a criminal trial, but they also realize, and only too well, that once given unlimited judicial approval the entire field immediately lends itself to prostitution by unethical and incompetent examiners. The fact that the method is nothing more nor less than a diagnostic technique, ${ }^{22}$ the value of which depends to a very considerable extent upon the competency of the examiner, and certainly to the same degree upon his integrity, entirely justifies the conservative position taken by the courts in the Frye and Bohner cases. In this field, more than in any of the others previously discussed, the remuneration for quackery is unlimited. With this consideration in view, the Scientific Crime Detection Laboratory of Northwestern University School of Law, which for the past five years has been the center of research and actual case work in this field, proposes only a conditional and restricted use of an instrument of this nature for court purposes-at least for the time being, and perhaps for quite some time to come. The prerequisite to the admissibility of such evidence should be a stipulation or agreement between counsel for prosecution and defense, made prior to the expert's examination, that the results and the expert's

${ }^{13}$ Id. at 47,293 Fed. at ro14.

${ }^{19} 210$ Wis. 651,246 N. W. 314 (1933).

${ }^{30}$ In this opinion there is a quotation from defense counsel to the effect that the defendant offered to prove "by Prof. Leonarde Keeler of Northwestern University . . . that the defendant . . . was not guilty." The language may convey the impression that Mr. Keeler actuaily conducted the tests, and participated in the case. As a matter of fact, however, he did not test the defendant. The extent of his participation consists of correspondence with defense counsel, in which Mr. Keeler consented merely to examine the defendant and to render a report to defendant's counsel.

${ }^{2}$ See Inbau, The "Lie-Detector" (1935) 40 The Scientific Montrux 81-87.

2 See Keeler, Debunking the "Lie-Detector" (1934) 25 J. CRIM. L. \& Crumin. 153-160. 
interpretation thereof are to be admitted without objection and regardless of whether they favor the cause of prosecution or defense. This, of course, presupposes an agreement between counsel upon the expert himself. In this way the probability of incompetent and unethical practices would be reduced to a minimum.

In a recent Wisconsin case, State v. Loniello and Grignano, ${ }^{23}$ the Circuit Court of Columbia County approved of such a stipulation and agreement as that outlined above and admitted so-called "lie-detector" records and also expert testimony concerning their interpretation. Along with this, of course, other evidence of the usual type was introduced. A conviction resulted but no appeal was taken by either defendant.

This analysis of court decisions might be extended to cover a much wider variety and number of cases involving scientific evidence, but those discussed thus far should serve to indicate that the courts of this country are ready and willing to adopt, though with caution, the otherwise recognised evidence which may result from the application of scientific methods to criminal investigations.

${ }^{3}$ February 7, I935, Judge Clayton F. Van Pelt presiding. See Inbau, Detection of Deception Technique Admitted as Evidence (1935) 26 J. CRIM. L. \& CRIMIN. 262-27I. 